\title{
Public Service Motivation and Performance Behavior in Saudi Public Sector: The Role of Subjective Fits
} Saleh Abdullah Alreshoodi

\author{
Assistant Professor, College of Business Administration, University of Hail, Hail, Saudi Arabia. \\ s.alreshoodi@uoh.edu.sa
}

Abstract: One of the main propositions of Public Service Motivation (PSM) theory is its positive impact on employee performance. Recent studies, however, demonstrated that this relationship is more complex and nuanced and may be mediated by additional factors. This study contributes to the existing literature by examining the mediating role of subjective fits in the PSM-performance relationship where performance is conceptualized as in-role and extra-role behaviors. Data collected from a survey of 358 public service employees from The General Directorate of Health Affairs in Hail Region, Saudi Arabia were analyzed with Structural Equation Modeling (SEM) testing for both direct and indirect relationships. The results demonstrated that PSM was directly associated with both in-role and extra-role behaviors. Further, perceived needs-supplies (N-S) fit partially mediated these relationships, while person-organization (P-0) fit mediated the relationship between PSM and in-role behaviors. In general, the study confirmed the complex nature of PSM-performance relationship and clarified the role of certain mediators. Practical and theoretical implications are discussed.

Keywords: PSM, person-organization fit, demands-abilities fit, needs-supplies fit, in-role behavior, extra-role behavior.

\section{INTRODUCTION}

Public Service Motivation (PSM) research has expanded tremendously since the publication of Perry and Wise's (1990) seminal work on motivational bases of public service(Ritz, Brewer, \& Neumann, 2016). One of the reasons for this is that, originating in public administration and management, PSM has demonstrated great potential in improving public service and public employee outcomes. Conceptually, PSM is recognized as a particular form of intrinsic motivation that leads to enjoying activities of helping others by focusing on the meaning, significance, and purpose of tasks (Perry et al., 2010; Petrovsky \& Ritz, 2014). It has also been linked to higher organizational commitment (Gould-Williams et al., 2013; Leisink \& Steijn, 2008; Park \& Rainey, 2007), stronger job satisfaction (Cerase \& Farinella, 2009; Kaipeng et al., 2014; Taylor, 2014) and lower turnover intentions (Campbell et al., 2014; Park \& Rainey, 2007; Steijn, 2008). Accordingly, PSM could be an essential tool of human resource management to promote both individual and organizational performance. Attracting and retaining employees with higher PSM levels is expected to improve performance because such employees are better motivated, work harder, collaborate better, and go beyond simple call of duty (Bellé, 2013;Mostafa et al., 2015; Van Loon et al., 2018; Vandenabeele, 2009).

And yet, there is no conclusiveness about the relationship between PSM and performance. Whereas some studies found PSM to be positively related to performance (Andersen et al., 2014; Bright, 2007; Mostafa et al., 2015; Vandenabeele, 2009), others failed to establish a significant relationship (Alonso \& Lewis, 2001; Petrovsky \& Ritz, 2014; Ritz, 2009). This suggests that additional factors may be in play. Indeed, a growing number of researchers have noted lately that the relationship between PSM and performance is likely more nuanced and complicated than Perry and Wise (1990) originally proposed (Miao et al., 2019; Lynggaard et al., 2018; van Loon et al., 2018). Specifically, it was suggested that the contextual differences in which such relationship is placed mattered (Lynggaard et al., 2018; van Loon et al., 2018; Vandenabeele, 2009). 
Person-Environment (P-E) Fit theory looks specifically into the match between individuals and environmental characteristics (French et al., 1982, Kristof-Brown et al., 2005). It, therefore, can aid in understanding the relationship between PSM and performance. Several PSM researchers proposed that P-E fit may offer concrete mechanisms in explaining PSM connection to beneficial outcomes for both employees and organizations (Bellé, 2013; Bright, 2007; Gould-Williams et al., 2013; Steijn, 2008). After connecting PSM and P-E fit theory conceptually, Ryu (2017) argued that P-E fit could lead to performance improvement by offering enjoyment of work through fit between employees and the working environments.

Empirical literature confirmed the positive effect of P-E fit in the PSM-employee outcomes relationship (i.e., Bright, 2007; Gould-Williams et al., 2013; Leisink \& Steijn, 2008; Kim, 2012; Mostafa et al., 2015; Taylor, 2008; Wright \& Pandey, 2008). Yet, empirical studies that have focused on P-E fit with a specific focus on performance are rare. This is especially true in relation to investigating different fits simultaneously (van Loon et al., 2015). This study aims to fill this gap in knowledge by analyzing the mediating effects of subjective fits person-organization (P-O) fit, demands-abilities (D-A) fit and needs-supplies(N-S) fit on the PM-performance relationship. By treating individual performance as a collection of behaviors benefiting the organization and the others (Williams \& Anderson, 1991), the study aimed to provide a more detailed view of different forms of fit for different forms of behavioral performance.

The rest of the article proceeds as follows. First, PSM and its relationship to performance is discussed with the focus on public sector. Next, the potential role of subjective fits in this relationship is discussed. The hypotheses are developed from the theoretical discussions. After that, the methods section describes the research approach and presents the conceptual framework. This is followed by presentation of the research results. The discussion section reviews the main findings in the context of the available knowledge. The final section draws conclusions and implications of both theoretical and practical character and offers directions for future research.

\section{THEORETICAL FRAMEWORK}

\section{Public Service Motivation}

Perry and Wise (1990) originally defined PSM as "an individual predisposition to respond to motives grounded primarily or uniquely in public institutions" (p. 368). It is, therefore, a concept that is distinctive to public administration and management (Meier, 2015; Moynihan et al., 2013; Perry \& Vandenabeele, 2015). In contrast to rational choice theories, PSM proposes that individuals in public organizations are driven not by mere selfinterest, but also by other factors, such as desire to participate in public service, feeling of duty, and compassion. At the same time, PSM-driven behavior is not purely altruistic, but rather based on a mixed motive of benefiting others while satisfying personal needs (Ritz et al., 2016). Vandenabeele (2007) related the institutional theory and the identity concept to argue that PSM motivates individuals to act according to what is seen as appropriate in organizational and societal contexts. He defined PSM as "the belief, the values and attitudes that go beyond self-interest and organizational interest, that concern the interest of a larger political entity and that motivate individuals to act accordingly whenever appropriate" (Vandenabeele, 2007, p. 549). This study adopts this definition to view PSM as a motivation in a specific context which is influenced by the organizational environment in which public service is performed.

\section{PSM and Performance}

Whereas PSM is predicted to enhance performance in public organizational context (Perry \& Wise, 1990; Kim, 2005), it is problematic to measure this impact at organizational level as a whole in a meaningful way. The reason for this is that it become difficult to apply common performance metrics across public organizations (Andrews et al., 2006; Brewer \& Selden, 2000). In contrast to profit-oriented private enterprises, public organizations often go beyond the quantifiable goals of effectiveness and efficiency (Boyne, 2002). They are likely to pursue different goals and objectives and use different financial targets to meet. Therefore, it is more appropriate to 
focus on individual performance as an outcome of PSM (Brewer, 2008; Gould-Williams et al., 2013; van Loon et al., 2018). It is also reasonable from a strategic human resource management point of view, because public organizations can develop practical tools to nurture employee motivation to obtain desired outcomes (Ritz et al., 2016).

Individual performance of public can be conceptualized in terms of in-role and extra-role behaviors. Inrole behavior refers to duties and responsibilities at the core of a job's assignment (Vigoda, 2000; Williams \& Anderson, 1991). Relative to public service employees, it can be seen as self-perception of how well one performs the prescribed job task requirements (van Loon et al., 2015). Researchers investigated both direct and indirect relationship between PSM and in-role behavior. A positive relationship between PSM and selfreported supervisor ratings (Bright, 2007) points to potentially better task performance among those who do public service and wish to contribute positively to society. At the same time, van Loon et al. (2015) found a positive significant relationship between PSM and in-role behavior among employees of a broad range of public organizations. Therefore, this study made the following proposition:

\section{H1: PSM is positively related to public service employees' in-role behavior.}

In contrast to in-role behavior, extra-role behavior goes beyond completion of the job tasks and assignments. It is defined as behavior which is "discretionary, not directly or explicitly recognized by the formal reward system, and in the aggregate promotes the efficient and effective functioning of the organization" (Organ, 1988, p.4). In other words, extra-role behavior encompasses neither formally required nor rewarded acts that benefit organizations and their goals (Smith et al., 1983). In the context of public service organizations, such behaviors are interchangeable with Organizational Citizenship Behavior (OCB), a widely recognized and well researched concept (Gould-Williams et al., 2013; Kim, 2006; Lemmon \& Wayne, 2015; Pandey, Wright, \& Moynihan, 2008). Following Vandenabeele's (2007) definition of PSM, public service employees with high PSM levels would be more likely to engage in extra-role behaviors to benefit society at large. Accordingly, previous research demonstrated the positive link between PSM and extra-role behavior in public organizations (Gould-Williams et al., 2013; Mostafa \& Leon-Cazares, 2016; Pandey et al., 2008; Shim \& Faerman, 2017; van Loon et al., 2015). Therefore, this study made the following proposition:

H2: PSM is positively related to public service employees' extra-role behavior.

\section{The Role of Subjective Fits}

Inconsistency of findings regarding PSM-performance relationship suggests that context may have an important role. This is one of the postulates of the institutional perspective on PSM (Moynihan et al., 2013; Perry \& Vandenabeele, 2008; Vandenabeele, 2007). Institutional theory in general asserts that individual behavior is shaped and directed by the institutional environment (Edwards, 2008; March \& Olsen, 1989). In the context of public organizations, such influence can be either positive or negative, and this can be translated into either promoting in-role and/or extra-role behaviors or suppressing them. Accordingly, PSM will enhance these behaviors only if the institutional environment is supportive and conducive to provision of meaningful public service (van Loon et al., 2015). Therefore, there must be a fit between personal views and motives driven by PSM and the environment within the respective public organizations.

P-E Fit theory is congruent with the institutional perspective on PSM and it offers important context links in the PSM-performance relationship. Kristof-Brown et al. (2005) broadly defined P-E fit as "the compatibility between an individual and a work environment that occurs when their characteristics are well matched" (p. 281). P-E fit is connected to both individual behavior and PSM. P-E fit theory proposes that individual behavior results from congruence between personal characteristics and working environment (Edwards, 2008; Ryu, 2017). Specifically, individuals differ in terms of personality, values and working environment perceptions. Better fit then leads to positive behavioral and organizational outcomes. At the same time, P-E fit is linked 
to PSM through the mechanism of value congruence in a sense that individuals with higher PSM would seek employment in public organizations where they subjectively believe that their values would match (Ryu, 2017). It also creates clear role expectations and reduces person-organization conflict thereby creating higher degree of commitment and satisfaction, essential to motivation and performance (Kalliath et al., 1999).

Within the P-E fit framework, objective fits are distinguished from subjective fits. Whereas objective fit refers to the degree of actual fit with the environment, subjective fit refers to how an individual perceives this match (van Loon et al., 2015). Studies showed that the perceived fit may matter more for employee outcomes than the actual work environment (Kristof-Brown et al., 2005). Within the PSM scholarship, subjective fits were found to mediate the relationship between PSM and employee outcomes including work attitudes, quit intentions, and organizational citizenship behavior (Gould-Williams et al., 2013; Kim, 2012; Wright \& Pandey, 2008). Most of these studies, however, considered subjective fit as a two-factor concept. Following Cable and DeRue (2002), this study considers subjective fit as a three-factor concept to offer a more detailed view on its mediating effect on the PSM-performance relationship. By demonstrating what types of fit matter for different performance behavior outcomes, it would be possible to develop more scientifically grounded practical suggestions for public organization human resource management.

Perceived person-organization (P-0) fit is the degree to which employees believe that their own values match the values, climate, and goals of the organization (Cable \& DeRue, 2002; Ryu, 2017). A positive perceived link between personal and organizational values is likely to result in prosocial behavior beyond one's prescribed job tasks (Cable \& DeRue, 2002; Erdogan \& Bauer, 2005). They are likely to perform their tasks better as well. However, whereas public organizations are more likely than private organizations to offer environment and opportunities to satisfy public service motives, not all of them actually do that (Wright \& Pandey, 2008). This could explain to some degree why some previous studies failed to identify a direct link between PSM and performance. The mediating role of P-O fit for employee outcomes including performance, has been confirmed, albeit to a different degree, by previous studies (Bright, 2007; Bright, 2008; Gould-Williams et al., 2013; Jin et al., 2018; Kim, 2012; van Loon et al., 2015; Wright \& Pandey, 2008). Therefore, the following proposition is made:

H3: P-O fit will mediate the relationship between PSM and a) in-role behavior, b) extra-role behavior.

Most studies of the role of subjective fits treat the person-job (P-J) fit as a single concept (e.g., Moynihan \& Pandey, 2008; Wright \& Pandey, 2008, van Loon et al., 2015). While recognizing its subconceptualization into demands-abilities (D-A) fit and needs-supplies (N-S) fit, PSM researchers rarely investigate their separate effects. However, there are reasons to believe that such partitioning is important. Subjective D-A fit can be conceptualized as a perceived congruence between job demands and one's abilities whereas subjective $\mathrm{N}-\mathrm{S}$ fit refers to how one perceives that the job satisfies personal preferences and desires (Edwards, 2008; Kristof-Brown et al., 2005). N-S fit emerged as a distinct concept in the theories of adjustment and satisfaction (Caplan, 1983; Kristof-Brown et al., 2005). Cable and DeRue (2002) successfully demarcated D-A and N-S fit to demonstrate their separate impact on various aspects of work outcomes. In the context of public organizations, both types of fits are expected to influence the PSM-performance relationship. Employees with high PSM may still lack the abilities to perform according to the demands of their job. Therefore, D-A fit is considered direct and most likely factor for improving individual performance in the long term (Cable \& DeRue, 2002). At the same time, if the job fails to satisfy personal desires, individual or society-focused, of employees with high PSM, they will unlikely to perform well either. Accordingly, the following propositions are made:

H4: perceived D-A fit will mediate the relationship between PSM and a) in-role behavior, b) extra-role behavior.

H5: perceived N-S fit will mediate the relationship between PSM and a) in-role behavior, b) extra-role behavior.

The conceptual framework for the study is presented in Figure 1.

American Research Journal of Business and Management Page 4 


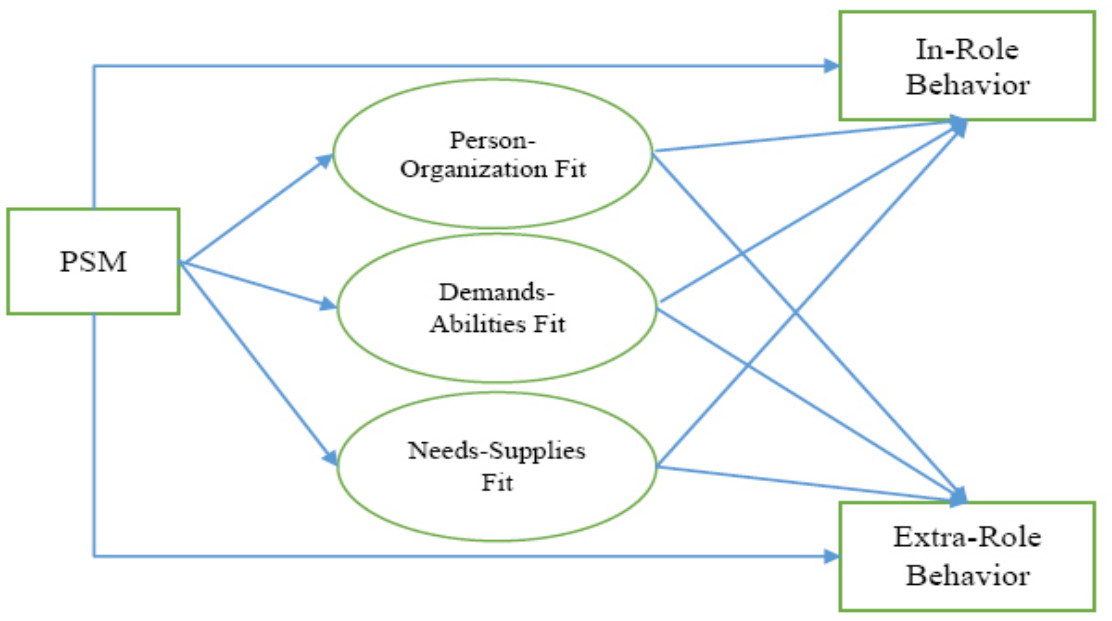

Fig1. Conceptual Framework

\section{METHOD}

Data for the study were obtained from the administrative employees working in The General Directorate of Health Affairs in Hail Region. This organization supervises 7 local hospitals. The number of employees is925.A web-based survey was used to collect data. The individuals were asked to participate in the survey by internal email and by posting a link on the internal organizational site. Data collection covered the period of April-May 2019. The survey was conducted in Arabic. Back-translating technique was used to translate the questionnaire items from English (Brislin, 1970). Pilot testing for the final questionnaire was run on a small sample of public sector employees. Based on the results, four out of seven original items were retained for in-role and extrarole behavior measures. Some items were found inapplicable. For example, there was no employee evaluation process in the organization. All remaining items showed Cronbach's alpha of at least 0.8.

Out of 925 employees, 370 completed the survey. Some questionnaires were discarded because of incomplete data bringing the final number of responses to 358. This gave an effective response rate of 38.8\%.Non-response bias was tested by comparing results of the first and last $10 \%$ of respondents (Armstrong, Scott,\& Overton, 1977). The results of t-test did not show statistically significant differences thus showing that non-response bias was not a concern.

Among the respondents, the majority were male (64.0\%), aged between 31 and 40 (47.5\%), holding a bachelor degree (57.1\%), and having work experience between 5 and 10 years (32.7\%). Further, 39.8\% of respondents held supervisory positions.One respondent did not provide personal data. A complete distribution of respondents by the aforementioned characteristics is presented in Table 1.

Table1. Descriptive Characteristics of the Sample

\begin{tabular}{|c|c|c|c|}
\hline Characteristic & Category & Frequency & Percentage \\
\hline \multirow{2}{*}{ Gender } & Male & 229 & $64.0 \%$ \\
\cline { 2 - 4 } & Female & 129 & $36.0 \%$ \\
\hline \multirow{3}{*}{ Age Group } & 18 to 30 & 94 & $26.3 \%$ \\
\cline { 2 - 4 } & 31 to 40 & 170 & $47.5 \%$ \\
\cline { 2 - 4 } & 41 to 50 & 69 & $7.3 \%$ \\
\cline { 2 - 4 } & over 50 & 25 & $30.9 \%$ \\
\hline \multirow{3}{*}{ Education } & High School & 111 & $57.1 \%$ \\
\cline { 2 - 4 } & Bachelor's & 205 & $8.6 \%$ \\
\cline { 2 - 4 } & Master's & 31 & $3.1 \%$ \\
\hline
\end{tabular}


Public Service Motivation and Performance Behavior in Saudi Public Sector: The Role of Subjective Fits

\begin{tabular}{|c|c|c|c|}
\hline \multirow{2}{*}{ Supervise Employees? } & Yes & 143 & $39.8 \%$ \\
\cline { 2 - 4 } & No & 215 & $59.9 \%$ \\
\hline \multirow{3}{*}{ Length of service } & 1 to 5 years & 92 & $25.7 \%$ \\
\cline { 2 - 4 } & 6 to 10 years & 102 & $28.5 \%$ \\
\cline { 2 - 4 } & 11 to 20 years & 117 & $32.7 \%$ \\
\cline { 2 - 4 } & over 20 years & 47 & $13.1 \%$ \\
\hline
\end{tabular}

\section{Measures}

The questionnaire consisted of 29 items (Appendix A). All measures in the study framework were 7-point Likert scale items ranging from 1 = "strongly disagree" to 7 = "strongly agree."

PSM was measured by Kim's (2009) 12-item questionnaire. The questionnaire was developed specifically for international PSM studies. It was successfully tested before in the context of Saudi public organizations (Alreshoodi, 2018). The instrument measures PSM across four dimensions: policy-making, commitment to the public interest, compassion, and self-sacrifice. Cronbach's alpha for the PSM dimensions ranged from0.724 to 0.810 .

Subjective fit measures were based on the items developed and validated by Cable and Judge (1996) and Cable and DeRue (2002). P-O fit was measured with three items, and reliability of the measure was 0.895. D-A fit was measured with three items, and reliability of the measure was 0.956 . Finally, N-S fit was measured with three items, and reliability of the measure was 0.708 .

In-role and extra-role behaviors measures were based on the items developed and validated by Williams and Anderson (1991). After pilot testing, four items were removed from each in-role and extra-role measures.The reliability measure of the remaining items was 0.881 for in-role behavior and 0.834 for extra-role behavior.

\section{RESULTS AND ANALYSIS}

Data analysis followed a two-step methodology where a measurement model analysis is followed by a structural model analysis (Anderson \& Gerbing, 1988; McDonald \& Ho, 2002). The analyses were conducted with SPSS and AMOS 26.

\section{Measurement Model Analysis}

Confirmatory factor analysis (CFA) was used to analyze reliability and validity of the six constructs in the conceptual model. First, the analyses were performed independently for the independent (PSM), mediating (subjective fits) and dependent (in-role and extra-role behaviors) variables. After that, CFA was run for the entire model with the correlations among all study constructs. Because the sample size was relatively large (over 200), the appropriate parameters for CPA was comparative fit index (CFI), root mean square error of approximation (RMSEA), standardized root mean square residual (SRMR) and Tucker-Lewis' index (TLI) (Kline, 2010; Williams et al., 2009). Generally, models require CFI and TLI of at least 0.9, and values of RMSEA and SRMR lower than 0.1 are considered acceptable (Hu \& Bentler, 1999; Kline, 2010).

The initial CPA for second-order measurement of PSM did not produce an acceptable model fit. A further analysis showed high crossloading levels for three items, which were removed: APM3 ("Seeing people get benefits from the public programme I have been deeply involved in brings me a great deal of satisfaction"); CPI2 ("Meaningful public service is very important to me"), and SS1 ("Making a difference in society means more to me than personal achievements"). After this, a fitting model was achieved $(\chi 2=74.6$ ( $\mathrm{df}=21 ; \mathrm{p}<0.001)$; CFI $=0.949$; TLI $=0.913 ;$ SRMR $=0.032$; RMSEA $=0.085$ ). Standardized factor loadings ranged between 0.68 and 0.9, all significant at the $\mathrm{p}<0.001$ level. Therefore, the model proved consistent with Kim's (2009) conceptualization of PSM. 
Public Service Motivation and Performance Behavior in Saudi Public Sector: The Role of Subjective Fits A three-dimensional model CFA was run for the mediating variables (P-O Fit, D-A Fit, and N-S Fit). The model was good $(\chi 2=70.74(\mathrm{df}=24 ; \mathrm{p}<0.001)$; CFI = 0.980; TLI = 0.971; SRMR = 0.067; RMSEA =0.074). Factor loadings for the measures ranged between 0.83 and 0.96 .

Finally, a two-dimensional model CFA was run for the dependent variables (in-role and extra-role behaviors). Two items were removed after the initial run due to high crossloadings: InRole1 ("I adequately complete assigned duties") and ExtraRole1 ("I help colleagues who have been absent at work for some time"). After that, the model demonstrated a good fit $(\chi 2=30.01$ ( $\mathrm{df}=8 ; \mathrm{p}<0.001)$; CFI = 0.984; TLI = 0.970; SRMR = 0.052; RMSEA $=0.088$ ). Factor loadings for the measures ranged between 0.76 and 0.93 .

A complete measurement model CFA was run for the constructs with the remaining items. An analysis of the modification indices (Byrne, 2012) showed that the final model would be improved after deletion of Comp2 item from the PSM measure ("I am often reminded by daily events how dependent we are on one another"). The final model demonstrated a good fit $(\chi 2=839.57$ ( $\mathrm{df}=194 ; \mathrm{p}<0.001)$; CFI = 0.944; TLI = 0.920; SRMR = 0.078; RMSEA $=0.097)$. A further analysis demonstrated high internal consistency based composite reliability scores over 0.7 and average variance extracted scores over 0.5 (Fornell\&Larcker, 1981). Table 2 shows the comparison of square root average variance extracted (AVE) for the study constructs against their correlations with every other construct to measure determinant validity (Fornell \& Larcker, 1981). As it is seen, in all cases, the former was higher than the latter which suggests that discriminant validity was satisfied.

Table2. Intercorrelations and Reliability Estimates

\begin{tabular}{|c|c|c|c|c|c|c|}
\hline Construct & PSM & P-O Fit & D-A Fit & N-S Fit & InRole & ExtraRole \\
\hline PSM & $0.578(0.924)$ & & & & & \\
\hline P-O Fit & 0.462 & $0.740(0.895)$ & & & & \\
\hline D-A Fit & 0.059 & -0.323 & $0.878(0.956)$ & & & \\
\hline N-S Fit & 0.108 & 0.638 & -0.375 & $0.537(0.748)$ & & \\
\hline InRole & 0.054 & 0.454 & -0.242 & 0.449 & $0.787(0.917)$ & \\
\hline ExtraRole & 0.26 & 0.251 & -0.0087 & 0.277 & 0.314 & $0.703(0.876)$ \\
\hline
\end{tabular}

Note: crossdiagonals show square root AVE against composite reliability (in brackets). Subdiagonals show inter correlations between constructs.

Finally, the model was estimated for the common method bias which arises when the shared statistical variance arises not from the constructs but from the measurement method itself (Podsakoff et al., 2003). Harman's single factor test was used where all items were loaded into a single factor. The resulting model demonstrated a poor fit $(\chi 2=3609.486$ (df = 209; $\mathrm{p}<0.001)$; CFI = 0.317; TLI = 0.246; SRMR = 0.287; RMSEA =0.213). Therefore, common method bias unlikely represented a serious issue in the study.

\section{Structural Model Analysis}

To test the hypotheses formulated in the study, two structural model analyses were performed with and without controlling variables of gender, age, education, supervision, and service. Both models demonstrated good fits. Because there is no strongly developed theory for including controls in such analyses, only the model without controls is reported here (Gould-Williams et al., 2013; Williams et al., 2009).

The structural model demonstrated a good fit to data $(\chi 2=191.43$ ( $\mathrm{df}=4 ; \mathrm{p}<0.001)$; CFI = 0.937; TLI = 0.926; SRMR =0.051; RMSEA = 0.062). Together, PSM and subjective fits explained $18.2 \%$ variation in in-role behavior and $12.4 \%$ variation in extra-role behavior based on $\mathrm{R}^{2}$ values. Additionally, PSM accounted for $18.3 \%$ variability in P-O Fit, but only for $2 \%$ in N-S Fit and no variability in D-A Fit.

American Research Journal of Business and Management Page 7 
Public Service Motivation and Performance Behavior in Saudi Public Sector: The Role of Subjective Fits Analysis of the individual paths in the model is presented in Table 3. PSM was positively associated with inrole behavior $(\beta=0.069, \mathrm{p}<.001)$ and with extra-role behavior $(\beta=0.228, \mathrm{p}<.001)$. Therefore, hypotheses 1 and 2 were supported by the study findings. Statistically significant, positive relationships were identified between PSM and P-O Fit ( $\beta=0.428, p<.001)$ and PSM and N-S Fit ( $\beta=0.140, p=0.007)$. P-O Fit was positively associated with in-role behavior $(\beta=0.190, \mathrm{p}<.001)$, while N-S Fit was positively associated with both in-role behavior $(\beta=0.331, \mathrm{p}<.001)$ and extra-role behavior $(\beta=0.241, \mathrm{p}<.001)$. Therefore, further analyses were conducted to determine whether there was mediation of in-role behavior by P-O Fit and both in-role and extrarole behaviors by N-S Fit.

Table3. Analysis of Individual Paths

\begin{tabular}{|c|c|c|}
\hline Relationship & \multicolumn{2}{|c|}{ Standardized Effect* } \\
\hline PSM->InRole & 0.069 & $\mathrm{p}<0.001$ \\
\hline PSM->ExtraRole & 0.228 & $\mathrm{p}<0.001$ \\
\hline PSM->P-O Fit & 0.428 & $\mathrm{p}<0.001$ \\
\hline PSM->D-A Fit & - & - \\
\hline PSM->N-S Fit & 0.140 & $\mathrm{p}=0.007$ \\
\hline P-O Fit->InRole & 0.190 & $\mathrm{p}<0.001$ \\
\hline P-O Fit->ExtraRole & - & - \\
\hline D-A Fit->InRole & - & - \\
\hline D-A Fit->ExtraRole & - & - \\
\hline N-S Fit->InRole & 0.331 & $\mathrm{p}<0.001$ \\
\hline N-S Fit->ExtraRole & 0.241 & $\mathrm{p}<0.001$ \\
\hline \multicolumn{2}{|c|}{$*$ only statistically significant relationships reported (p<0.05) } \\
\hline
\end{tabular}

A Sobel test with bootstrapped standard errors based on 1000 resampling was used for mediation tests (MacKinnon et al., 2002). The mediated PSM effect on extra-role was $0.140 * 0.241=0.038$ (Sobel test 2.32; $\mathrm{p}=$ $0.02)$. The ratio to total effect was $0.038 /(0.038+0.228)=0.143$. Therefore, about $14.3 \%$ of the combined PSM and N-S Fit effect on extra-role behavior was explained by the indirect path via N-S Fit. This suggests that the direct path was dominant and that there could be other mediators in play.

The same procedure was applied to test for mediating effects on in-role behaviors. Two mediators were in play: P-O Fit and N-S Fit. When P-O Fit factor was considered, the mediated effect of PSM on in-role behavior was $0.428 * 0.190=0.081$ (Sobel test $3.35, \mathrm{p}<0.001$ ). The ratio to total effect was $0.081 /(0.081+0.069)=0.54$. When N-S Fit was considered, the mediated effect of PSM on in-role behavior was $0.140 * 0.331=0.046$ (Sobel test 2.47, $\mathrm{p}=$ $0.01)$. The ratio to total effect was $0.046 /(0.046+0.069)=0.4$. Therefore, both P-O Fit and N-S Fit demonstrated mediating effects. The indirect path through P-O Fit was dominant. Overall, the results of mediation analyses fully supported Hypothesis 5 (N-S mediation of both in-role and extra-role behavior), partially supported Hypothesis 4 (P-O Fit mediated in-role behavior but not extra-role behavior), and did not support Hypothesis 3 (D-A Fit did not demonstrate mediating effects). Table 4 presents a summary of mediation tests.

Table4. Summary of Mediation Tests Results

\begin{tabular}{|c|c|c|c|}
\hline Mediated Relationship & Indirect Path Coefficient & Indirect to Total Effect Ratio & Sobel Test \\
\hline PSM->P-O Fit->InRole & 0.081 & 0.540 & $3.35(\mathrm{p}<0.001)$ \\
\hline PSM->N-S Fit->InRole & 0.046 & 0.400 & $2.47(\mathrm{p}=0.01)$ \\
\hline PSM->N-S Fit->ExtraRole & 0.038 & 0.143 & $2.32(\mathrm{p}=0.02)$ \\
\hline
\end{tabular}

American Research Journal of Business and Management

Page 8 


\section{DISCUSSION}

This study contributed to the existing research in the field of PSM by investigating the role of subjective fits in the relationship between PSM and performance behaviours. By demonstrating statistically significant direct and indirect paths in this relationship, this research aligns well with the growing body of literature suggesting a nuanced and complex relationship between PSM and performance (Lynggaard et al., 2018; Miao et al., 2019; van Loon et al., 2018; Vandenabeele, 2009). The demonstrated relationships, even though somewhat modest, are still important given that performance is influenced by multiple factors (Hoffman et al., 1991; van Loon et al., 2015). Overall, the research presents several important findings, which are discussed below.

First, this study findings confirmed a positive direct relationship between PSM and individual performance. The findings align well with the previous research that conceptualized performance as in-role and extra-role behaviors, both in general organizational literature and literature related to PSM (Cable \&DeRue, 2002; van Loon et al., 2015; van Loon et al., 2018). A notable finding in this regard is a much stronger relationship of PSM to extra-role behaviors which indicates that employees with high levels of PSM are even stronger motivated to engage in extra-task performances than in the core task assignments. In fact, strong relationships between PSM and organizational citizenship behavior, a different name for extra-role behavior, are well documented in literature (Gould-Williams et al., 2013; Kim 2006; Pandey et al., 2008). Still, both types of behavior are considered essential to performance (Brewer \& Selden, 2000; Podsakoff et al., 1997; van Loon et al., 2015). Therefore, contribution of PSM to both in-role and extra-role behaviors is an important finding in this study.

At the same time, the study built successfully on the institutional perspective on PSM and the existing research that demonstrated the importance of P-E Fit in the PSM-performance relationship (Bright, 2013; Gould-Williams et al., 2013; Kim 2012; van Loon et al., 2018). Similar to those studies, this research demonstrated that hiring PSM-high employees is probably not sufficient to guarantee their good performance in public organizations. Creating an appropriate context and ensuring fits between personal motives and organizational environment and goals is likely to be important.

A strong contribution is made by partitioning the subjective P-J fit into demands abilities fit and needs supplies fit for the analysis of mediation. Most PSM research still treats P-J fit as a single concept (e.g., Gould-Williams et al., 2013; Moynihan \& Pandey, 2007; Wright \& Pandey, 2008, van Loon et al., 2015). However, the results of this research showed that while N-S fit is an important mediator for both in-role and extra-role behavior, D-A fit does not play a role in either. This suggests that behaviors and performance of individuals with high PSM is path dependent on how they perceive that the job satisfies personal preferences and desires (Edwards, 2008; Kristof-Brown et al., 2005) and less so on how they perceive their abilities are matching the demands of the job. This applies to both completing the job tasks and engaging in activities beyond job description. This, however, aligns well with the view of PSM as an internal attribute which motivates to perform well and do more when the work is found meaningful and contributing to a greater cause.

Consequently, the absence of relationships with D-A Fit also points towards importance of distinguishing the two types of fit in the P-J construct. In literature, D-A is associated more with material rewards such as expectations of pay increases (Cable \& DeRue, 2002; Ryu, 2017). While such things may be important for rational individuals in the private sector organizations or those who choose public service for job security and pay, they are less consistent with PSM motivated individuals who are more concerned about contribution and treat value congruence with organization higher than material rewards. On the other hand, personal perceptions of D-A fit may not be perfect (Cable \&DeRue, 2002). This could lead to inaccurate presentations of the fit by individuals and, therefore, inaccurate evaluations. In any case, additional research to clarify the role of D-A fit in PSM and employee performance in public organization is called for.

American Research Journal of Business and Management Page 9 
A rather interesting finding was the absence of mediating role of P-O fit in the PSM-extra-role behavior relationship. This seems to go contrary to the previously confirmed role of P-O fit for organizational citizenship behavior (Bright, 2008; Gould-Williams et al., 2013; Jin et al., 2018; Kim, 2012; Wright \& Pandey, 2008). However, it should be noted that all those studies considered P-O fit as a single mediating factor while this research investigated simultaneous effect of several subjective fits. In fact, a recent study by van Loon et al. (2015) failed to find a mediating effect of P-O fit on PSM-extra-role relationship while investigating simultaneous mediating effects of both P-O fit and P-J fit. Perhaps further research will offer more insights into the exact role of P-O fit for different types of behaviors.

\section{CONCLUSIONS}

This paper may offer some important implications for public sector management. It confirmed the importance of PSM for performance in the public sector through the mechanism of enhancing in-role and extra-role behaviours. Therefore, selection and retaining of employees with high level of PSM is desirable for good organizational performance. However, at the same time the study demonstrated that by itself PSM may offer only limited effect. If managers of public organizations desire to uncover the potential of PSM to a full extent, they need to create and maintain an organizational environment that commensurate with the values of these employees. Such actions may also help both newcomers and the existing employees internalize organizational values and channel them into public service (Bright, 2007). Further, to ensure value congruence, management should consider such actions as adequate training, communication of organizational values and priorities, and individual appraisals (Gould-Williams et al., 2013). Such actions should lead to creating awareness of role importance and importance of contribution to both organization and the public.

Some important implications may be drawn in reference to Saudi public sector specifically. Training and individual appraisals are not common in Saudi public organizations, which may impede realization of PSM potential. Further, an important aspect to consider is the presence of negative institutional forces that may influence organizational performance even among employees with high levels of PSM. For example, wasta, a form of Arab nepotism, was previously found common in Saudi public organizations, acting as a strong moderator to the relationship between PSM and positive employee outcomes (Alreshoodi, 2018). Adopting strict codes of conduct and practices would benefit Saudi public organizations from this standpoint. At the same time, in a highly collectivistic and religious society like Saudi Arabia, an interplay between PSM and both Islamic and collectivistic values is unavoidable. Whether these values actually support PSM values or may be in conflict with them is also a promising avenue for research.

The results of this study should be considered in light of some limitations. Because this research represented a cross-sectional study, no causality claims can be made. Therefore, the relationship results should be considered with caution and treated as associations. Longitudinal studies offer a better study design for causality claims, although they are more difficult to carry out. Further, self-reported values are generally prone to biases such as common method or social desirability (Meier \& O'Toole, 2013). Several actions were directed to reduce these. The data collection process guaranteed and communicated clearly anonymity to the respondents. They also had an option not to answer questions in the "personal background" category. The items in the survey were randomized so that the related items were not close to each other. Still, eve these actions might not have guaranteed objectivity of the respondents. Finally, this study was conducted in a specific cultural context which may be prone to additional influencing factors that remained outside of the research. However, most of the findings aligned with the previous similar studies conducted in different contexts. Therefore, to some extent, the findings could be generalized. Overall, the findings of the study supported the importance of PSM in public service management while at the same time showing importance of subjective fits and, by association, environmental context in linking PSM to performance.

American Research Journal of Business and Management

Page 10 
Public Service Motivation and Performance Behavior in Saudi Public Sector: The Role of Subjective Fits ApPEndix A: ORiginal Questionnaire ITEMS AND Scales

\begin{tabular}{|c|c|c|c|c|}
\hline \multicolumn{2}{|c|}{ Constructs and Items } & Mean & SD & FL \\
\hline \multirow{16}{*}{ PSM } & Attraction to policymaking & & & \\
\hline & $\begin{array}{l}\text { I am interested in making public programmes that are beneficial for my country } \\
\text { or the community to which I belong }\end{array}$ & 6.27 & 0.788 & 0.56 \\
\hline & Sharing my views on public policies with others is attractive to me & 6.28 & 0.752 & 0.64 \\
\hline & $\begin{array}{l}\text { Seeing people get benefits from the public programme I have been deeply } \\
\text { involved in brings me a great deal of satisfaction* }\end{array}$ & 6.59 & 0.637 & - \\
\hline & Commitment to public interest & & & \\
\hline & I consider public service my civic duty & 6.41 & 0.683 & 0.74 \\
\hline & Meaningful public service is very important to me & 6.69 & 0.552 & - \\
\hline & $\begin{array}{l}\text { I would prefer seeing public officials do what is best for the whole community } \\
\text { even if it harmed my interests* }\end{array}$ & 6.15 & 1.095 & 0.62 \\
\hline & Compassion & & & \\
\hline & It is difficult for me to contain my feelings when I see people in distress & 6.36 & 0.726 & 0.72 \\
\hline & I am often reminded by daily events how dependent we are on one another & 6.60 & 0.617 & 0.85 \\
\hline & I feel sympathetic to the plight of the underprivileged & 6.78 & 0.468 & - \\
\hline & Self-sacrifice & & & \\
\hline & Making a difference in society means more to me than personal achievements & 6.03 & 0.906 & - \\
\hline & I am prepared to make enormous sacrifices for the good of society & 5.87 & 0.905 & 0.73 \\
\hline & I believe in putting duty before self & 5.96 & 0.911 & 0.85 \\
\hline \multirow{3}{*}{ P-O Fit } & $\begin{array}{l}\text { The things that I value in life are very similar to the things that my organization } \\
\text { values }\end{array}$ & 5.66 & 1.200 & 0.85 \\
\hline & My personal values match my organization's values and culture & 5.66 & 1.193 & 0.90 \\
\hline & $\begin{array}{l}\text { My organization's values and culture provide a good fit with the things that I } \\
\text { value in life }\end{array}$ & 5.58 & 1.171 & 0.83 \\
\hline \multirow{3}{*}{ D-A Fit } & $\begin{array}{l}\text { The match is very good between the demands of my job and my personal } \\
\text { skills }\end{array}$ & 3.91 & 1.794 & 0.95 \\
\hline & My abilities and training are a good fit with the requirements of my job & 3.89 & 1.813 & 0.96 \\
\hline & $\begin{array}{l}\text { My personal abilities and education provide a good match with the demands } \\
\text { that my job places on me }\end{array}$ & 4.18 & 1.706 & 0.90 \\
\hline \multirow{3}{*}{ N-S Fit } & $\begin{array}{l}\text { There is a good fit between what my job offers me and what I am looking for } \\
\text { in a job }\end{array}$ & 5.29 & 1.368 & 0.89 \\
\hline & The attributes that I look for in a job are fulfilled very well by my present job & 4.99 & 1.483 & 0.86 \\
\hline & $\begin{array}{l}\text { The job that I currently hold gives me just about everything that I want from } \\
\text { a job }\end{array}$ & 6.47 & 0.758 & 0.88 \\
\hline \multirow{4}{*}{$\begin{array}{l}\text { In-Role } \\
\text { Behavior }\end{array}$} & I adequately complete assigned duties* & 6.42 & 0.805 & - \\
\hline & I fulfil responsibilities prescribed in my job description & 6.42 & 0.869 & 0.88 \\
\hline & I perform tasks that are expected of me & 6.33 & 1.055 & 0.83 \\
\hline & I meet the formal performance requirements of my job & 6.30 & 0.933 & 0.95 \\
\hline \multirow{4}{*}{$\begin{array}{l}\text { Extra- } \\
\text { Role } \\
\text { Behavior }\end{array}$} & I help colleagues who have been absent at work for some time* & 6.34 & 0.767 & - \\
\hline & I help colleagues who have heavy workloads & 5.76 & 1.031 & 0.76 \\
\hline & I assist supervisors in their work (when not asked) & 5.98 & 1.030 & 0.89 \\
\hline & I do my best to help new employees even when not required & 6.23 & 0.940 & 0.86 \\
\hline
\end{tabular}




\section{REFERENCES}

1. Alonso, P., \& Lewis, G. B. (2001). Public service motivation and job performance: Evidence from the federal sector. American Review of Public Administration, 31, 363-380.

2. Alreshoodi, S. (2018). Public Service Motivation, wasta, and employee outcomes in the Saudi public sector. Arabian Journal of Business Management, 8(3), 1-9.

3. Andersen, L. B., Heinesen, E., \& Pedersen, L. H. (2014). How does public service motivation among teachers affect student performance in schools?Journal of Public Administration Research and Theory, 24, 651-671.

4. Anderson, J. C., \& Gerbing, D. D. (1988). Structural equation modelling in practice: A review and recommended two-step approach. Psychological Bulletin 103 (3), 411-423.

5. Andrews, R., Boyne, G. A., \& Walker, R. M. (2006). Subjective and objective measures of organizational performance: An empirical exploration. In Boyne, A., Meier, K. J., O’Toole, L. J., Walker, R. M. (Eds.), Public service performance (pp.14-34).Cambridge, UK:Cambridge University Press.

6. Armstrong, J. C., \& Overton, T. S. (1977). Estimating nonresponse bias in mail surveys. Journal of Marketing Research, 14 (3), 396-402.

7. Bellé, N. (2013). Experimental evidence on the relationship between public service motivation and job performance. Public Administration Review, 73, 143-153

8. Boyne, G. A. (2002). Concepts and indicators of local authority performance: An evaluation of the statutory framework in England and Wales. Public Money \& Management, 22(4), 17-24.

9. Brewer, G. A. (2008). Employee and organizational performance. In J. L. Perry \& A. Hondeghem (Eds.), Motivation in public management: The call of public service (pp. 136-156). Oxford, UK: Oxford University Press.

10. Brewer, G. A., \& Selden, S. C. (2000). Why elephants gallop: Assessing and predicting organizational performance in federal agencies. Journal of Public Administration Research and Theory, 10, 685-711.

11. Bright, L. (2007). Does person-organization fit mediate the relationship between public service motivation and the job performance of public employees? Review of Public Personnel Administration, 27, 361-379.

12. Bright, L. (2008) Does public service motivation really make a difference on the job satisfaction and turnover intentions of public employees? American Review of Public Administration, 38, 149-166.

13. Bright, L. (2013). Where does public service motivation count the most in government work environments? A preliminary empirical investigation and hypotheses. Public Personnel Management, 42, 5-26.

14. Brislin, R.W. (1970). Back-translation for cross-cultural research. Journal of Cross-Cultural Psychology, 1, 185-216

15. Byrne, B. M. (2012). Structural equation modeling with Mplus. New York, NY: Taylor \& Francis Group.

16. Cable, D. M., \& DeRue, D. S. (2002). The convergent and discriminant validity of subjective fit perceptions. Journal of Applied Psychology, 87, 875-884.

17. Cable, D. M., \& Judge, T. A. (1996). Person-organization fit, job choice decisions, and organizational entry. Organizational Behavior and Human Decision Processes, 67, 294-311.

18. Campbell, J. W., Im, T., \& Jeong, J. (2014). Internal efficiency and turnover intention: Evidence from local government in South Korea. Public Personnel Management, 43, 259-282.

19. Caplan, R.D. (1983). Person-environment fit and organizations: commensurate dimensions, time perspectives, and mechanisms. Journal of Vocational Behavior, 31, 248-267. 
20. Cerase, F. P., \& Farinella, D. (2009). Public service motivation: How does it relate to management reforms and changes in the working situation of public organizations? A case study of the Italian revenue agency. Public Policy and Administration, 24 (3), 281-308.

21. Edwards, J. R. (2008). Person-environment fit in organizations: An assessment of theoretical progress. Academy of Management Annals, 2(1), 167-230.

22. Erdogan, B., \& Bauer, T.N. (2005). Enhancing career benefits of employee proactive personality: The role of fit with jobs and organizations. Personnel Psychology, 58 (4), 859-891.

23. Fornell, C., \& Larcker, D.F. (1981). Evaluating structural equation models with unobservable variables and measurement error. Journal of Marketing Research, 18 (1), 39-50.

24. French, J., Caplan, R.D., \& Harrison, R.V. (1982). The mechanisms of job stress and strain. Chichester: Wiley.

25. Gould-Williams, J. S., Mostafa, A. M. S., \& Bottomley, P. (2013). Public service motivation and employee outcomes in the Egyptian public sector: Testing the mediating effect of person-organization fit. Journal of Public Administration Research and Theory, 25(2), 597-622.

26. Hoffman, C. C., Nathan, B. R., \& Holden, L. M. (1991). A comparison of validation criteria: Objective versus subjective performance measures and self- versus supervisor ratings. Personnel Psychology, 44, 601-618.

27. Hu, L., \& Bentler, P. M. (1999). Cutoff criteria for fit indexes in covariance structure analysis: Conventional criteria versus new alternatives. Structural Equation Modeling: A Multidisciplinary Journal, 6, 1-55.

28. Jin, M. H., McDonald, B., \& Park, J. (2018). Does public service motivation matter in public higher education? Testing the theories of person-organization fit and organizational commitment through a serial multiple mediation model. The American Review of Public Administration, 48(1), 82-97.

29. Kaipeng, G., Jun, M., \& Xuefei, D. (2014) Research on the impact of public servicemotivation on job satisfaction: Taking the Chinese civil servants for example. In The Proceedings of International Conference on Public Management (ICPM),pp: 275-281.

30. Kalliath, T.J., Bluedorn, A. C., \& Strube, M.J.(1999). A test of value congruence effects. Journal ofOrganizational Behavior, 20, 1175-1198.

31. Kim, S. (2005). Individual-level factors and organizational performance in government organizations. Journal of Public Administration Research and Theory, 15 (2), 245-261.

32. Kim, S. (2006). Public service motivation and organizational citizenship behavior in Korea. International Journal of Manpower, 27, 722-740.

33. Kim, S. (2009). Revising Perry's measurement scale of public service motivation. American Review of Public Administration, 39, 149-163.

34. Kim, S. (2012). Does person-organization fit matter in the public sector? Testing the mediating effect of person-organization fit in the relationship between public service motivation and work attitudes. Public Administration Review, 72, 830-840.

35. Kline, R. B. (2010). Principles and practice of structural equation modeling. New York, NY: Guilford Press.

36. Kristof-Brown, A. L., Zimmerman, R. D., \& Johnson, E. C. (2005). Consequences of individual's fit at work: A meta-analysis of person-job, person-organization, person-group and person-supervisor fit. Personnel Psychology, 58, 281-342. 
37. Leisink, P. L. M., \& Steijn, B. (2008). Public service motivation and job performance of public sector employees in the Netherlands. International Review of Administrative Sciences, 75, 35-52.

38. Lemmon, G., \& Wayne, S.J. (2015). Underlying motives of organizational citizenship behavior: comparing egoistic and altruistic motivations. Journal of Leadership and Organizational Studies, 22(2), 129-148.

39. Lynggaard, M., Pedersen, M.J., \& Andersen, L.B. (2018). Exploring the context-dependency of the PSMperformance relationship. Review of Public Personnel Administration, 38(3), 332-354.

40. MacKinnon, D. P., Lockwood, C. M., Hoffman, J. M., West, S. G., \& Sheets, V. (2002). A comparison of methods to test mediation and other intervening variable effects. Psychological Methods, 7(1), 83-104.

41. March, J.G., \& Olsen, J. (1989). Rediscovering institutions: The organizational basis of politics. New York: Free Press.

42. McDonald, R. P., \& Ho, M.-H. R. (2002). Principles and practice in reporting structural equation analyses. Psychological Methods, 7, 64-82.

43. Meier, K. J.(2015). Proverbs and the evolution of public administration. Public Administration Review, 75(1), 15-24.

44. Meier, K. J., \& O’Toole, L. J. (2013). Subjective organizational performance and measurement error: Common source bias and spurious relationships. Journal of Public Administration Research and Theory, 23, 429-456.

45. Miao, Q., Eva N., Newman, A., \& Schwarz, G. (2019) Public service motivation and performance: The role of organizational identification. Public Money \& Management, 39 (2), 77-85.

46. Mostafa, A., \& Leon-Cazares, F. (2016). Public Service Motivation and organizational performance in Mexico: Testing the mediating effects of organizational citizenship behaviors. International Journal of Public Administration, 39(1), 40-48.

47. Mostafa, A., Gould-Williams, J.S., \& Bottomley, P. (2015). High-performance human resource practices and employee outcomes: The mediating role of Public Service Motivation. Public Administration Review, 75(5), 747-757.

48. Moynihan, D. P., \& Pandey, S. K. (2007). The ties that bind: Social networks, person-organization value fit, and turnover intention. Journal of Public Administration Research and Theory, 18, 205-227.

49. Moynihan, D. P., Vandenabeele, W., \& Blom-Hansen, J. (2013). Advancing Public Service Motivation research. Public Money and Management, 33(4), 288-289.

50. Organ, D.W. (1988). Organizational citizenship behavior: The good soldier syndrome. Lexington, MA: Lexington Books.

51. Pandey, S. K., Wright, B. E., \& Moynihan, D. P. (2008). Public service motivation and interpersonal citizenship behaviour in public organizations: Testing a preliminary model. International Public Management Journal, 11, 89-108.

52. Park, S.M., \& Rainey, H.G. (2007). Antecedents, mediators, and consequencesof affective, normative, and continuance commitment: Empirical tests ofcommitment effects in federal agencies. Review of Public Personnel Administration, 27, 197-226.

53. Perry, J. L., \& Vandenabeele, W. (2008). Behavioral dynamics: Institutions, identities and self-regulation. In J. L. Perry \& A. Hondeghem (Eds.), Motivation in public management: The call of public service (pp. 56-79). Oxford, UK: Oxford University Press. 
Public Service Motivation and Performance Behavior in Saudi Public Sector: The Role of Subjective Fits

54. Perry, J. L., \& Wise, L. R. (1990). The motivational bases of public service. Public Administration Review, 75, 53-78.

55. Perry, J. L., Hondeghem, A., \& Wise, L.R. (2010). Revisiting the motivational bases of public service: Twenty years of research and an agenda for the future. Public Administration Review, 70 (5), 681-690.

56. Perry, J.L., \& Vandenabeele, W. (2015). Public Service motivation research: Achievements, challenges, and future directions. Public Administration Review, 75(5), 692-699.

57. Petrovsky, N., \& Ritz, A. (2014). Public service motivation and performance: A critical perspective. EvidenceBased HRM, 2(1), 57-79.

58. Podsakoff, P. M., Ahearne, M., \& MacKenzie, S. B. (1997). Organizational citizenship behavior and the quantity and quality of work group performance. Journal of Applied Psychology, 82, 262-270.

59. Podsakoff, P. M., MacKenzie, S. B., Lee, J., \& Podsakoff, N. P. (2003). Common method bias in behavioral research: A critical review of the literature and recommended remedies. Journal of Applied Psychology, 88, 879-903.

60. Ritz, A. (2009). Public service motivation and organizational performance in Swiss federal government. International Review of Administrative Sciences, 75, 53-78.

61. Ritz, A., Brewer, G. A., \& Neumann, O. (2016). Public service motivation: a systematic literature review and outlook. Public Administration Review, 76(3), 414-426.

62. Ryu, G. (2017). Rethinking Public Service Motivation from the perspective of person-environment fit: complementary or supplementary relationship? Review of Public Personnel Administration, 37(3), 351368.

63. Shim, D.C., \& Faerman, S. (2017). Government employees' organizational citizenship behavior: the impacts of Public Service Motivation, organizational identification, and subjective OCB norms. International Public Management Journal, 20(4), 531-559.

64. Smith, C. A., Organ, D. W., \& Near, J. P. (1983). Organizational citizenship behavior: Its nature and antecedents. Journal of applied psychology, 68(4), 653-663.

65. Steijn, B. (2008). Person-environment fit and public service motivation.International Public Management Journal, 11. 13-27

66. Taylor, J. (2008). Organizational influences, public service motivation and work outcomes: An Australian study. International Public Management Journal, 11(1), 67-88.

67. Taylor, J. (2014). Public service motivation, relational job design, and job satisfaction in local government. Public Administration, 92, 902-918.

68. Van Loon, N. M., Vandenabeele, W., \& Leisink, P. (2015). Clarifying the relationship between Public Service Motivation and in-role and extra-role behaviors: the relative contributions of person-job and personorganization fit. American Review of Public Administration, 47(6), 699-713.

69. Van Loon, N., Kjeldsen, A.M., Andersen, L.B., Vandenabeele, W., \& Leisink, P. (2018). Only when the societal impact potential is high? A panel study of the relationship between Public Service Motivation and perceived performance. Review of Public Personnel Administration, 38(2), 139-166.

70. Vandenabeele, W. (2007). Toward a public administration theory of public service motivation. Public Management Review, 9(4), 545-556.

American Research Journal of Business and Management Page 15 
Public Service Motivation and Performance Behavior in Saudi Public Sector: The Role of Subjective Fits

71. Vandenabeele, W. (2009). The mediating effect of job satisfaction and organizational commitment on selfreported performance: More robust evidence of the PSM-performance relationship. International Review of Administrative Sciences, 75, 11-34.

72. Vigoda, E. (2000). Internal politics in public administration systems an empirical examination of its relationship with job congruence, organizational citizenship behavior, and inrole performance. Public Personnel Management, 29(2), 185-210.

73. Williams, L. J., \& Anderson, S. E. (1991). Job satisfaction and organizational commitment as predictors of organizational citizenship and in-role behaviors. Journal of Management, 17, 601-617.

74. Williams, L. J., Vandenberg, R. J., \& Edwards, J. R. (2009). Structural equation modeling in management research: A guide for improved analysis. The Academy of Management Annals, 3 (1), 543-604.

75. Wright, B. E., \& Pandey, S. K. (2008). Public service motivation and the assumption of person-Organization fit. Administration \& Society, 40, 502-521.

Citation: Alreshoodi, S, A,. "Public Service Motivation and Performance Behavior in Saudi Public Sector: The Role of Subjective Fits". American Research Journal of Business and Management. 2019; 5(1): 1-16.

Copyright (C) 2019 Alreshoodi, S, A,. This is an open access article distributed under the Creative Commons Attribution License, which permits unrestricted use, distribution, and reproduction in any medium, provided the original work is properly cited. 